\title{
SYSTEMIC STRATEGIC MANAGEMENT FOR VBES IN THE MANUFACTURING SECTOR
}

\author{
Heiko Duin \\ BIBA - Bremer Institut für Produktion und Logistik GmbH, GERMANY \\ du@biba.uni-bremen.de
}

\begin{abstract}
The concept of Virtual Organisation Breeding Environment (VBE) is now understood as a fundamental entity to enable the formation of dynamic collaborative organisations especially Virtual Organisations (VOs).

System theory fits well when dealing with dynamic and complex systems such as organisations. Therefore, the system theoretic or systemic view is adequate for analysing the internal and external challenges as well as the manoeuvring spaces for VBEs under dynamic circumstances. The VBE can be considered as a system of members who form a larger unit - the VBE itself - and which is embedded in a larger system, i.e. the market. The single members of a VBE which are normally companies can also be seen as (sub-) systems which build up the VBE. Strategic management has the function to identify the mid-and long-term objectives of the VBE including supportive strategic programmes (actions) to ensure the evolution of the network.

Based on a requirements analysis of a theoretic VBE, this paper provides a short state of the art on systemic approaches used in strategic management of manufacturing enterprises and how they can be transferred to collaborative organisations like VBEs. The result is a proposal of a strategic management process for VBEs supported by systemic methods and tools.
\end{abstract}

\section{INTRODUCTION}

Today, many manufacturing systems are subject to enormous pressures because of the ever changing market environments showing e.g. discontinuities in trends and globalisation. Manufacturers have responded to these conditions by forming collaborative relationships to suppliers, distributors and even customers (e.g. Jagdev and Thoben, 2001; p. 31). When two or more enterprises collaborate, they form a collaborative (enterprise) network.

Collaborative networks can be divided into long-term strategic networks and goal-oriented networks. Examples for long-term networks are Professional Virtual Communities or Industrial Clusters, while goal oriented networks may be further divided into grasping-opportunity driven (e.g. Virtual Enterprise, Extended Enterprise) and continuous-production driven networks like Supply Chains (CamarinhaMatos and Afsarmanesh, 2006)

Two basic types of collaborative networks are represented by Virtual Organisations (VOs) and by Source Networks (Kürümlüoglu et al., 2005): 
- A Virtual Organisation (VO) is a temporary consortium of partners from different organisations established to fulfil a value adding task, for example a product or service to a customer. The lifetime of a VO is typically restricted: it is created for a definite task and dissolved after the task has been completed. A synonym for VO is the term Virtual Enterprise.

- A Source/Support Network is a more stationary, though not static, group of organisational entities which has developed a preparedness to collaborate in case of a specific task / customer demand. Another name for such a network is Breeding Environment.

The relationship between these two forms is that the Breeding Environment prepares the instantiation of VOs. It acts as an incubator for a VO. From the VO point of view, the VO is created when a business opportunity occurs. In order to perform the actual value creation task, the VO can be created from scratch (collecting cooperating partners from an "open universe" of enterprises) or through a VO Breeding Environment (VBE).

This paper proposes a strategic management approach for such strategic alliances, especially VBEs, based on a systemic point of view.

\section{RELATION TO EXISTING THEORIES AND WORK}

\subsection{The Systemic View}

The idea to develop a theory of systems - or a general systems theory - has been introduced by Bertalanffy in the 50ies of last century. His efforts were published in his very well regarded book General Systems Theory - Foundations, Development, Applications (Bertalanffy, 1968). It can be seen as an interdisciplinary field of science and the study of the nature of complex systems in nature, society, and science.

In Europe, the principles of systems have been applied to the management of organisations by Hans Ulrich resulting in the St.-Gallener Management Model (e.g. Ulrich and Krieg, 1972). Ulrich considered an organisation as a goal-oriented social system. Management is the shaping and directing of such systems on any level (strategic, tactical, and operational) resulting in a system-oriented management science (Ulrich, 1984; p. 11).

In the US, Jay Forrester created the field of Systems Dynamics, where he introduced the modelling socio-economic inter-relationships within organisations by systems of differential equations (e.g. Forrester, 1968). Peter Senge based his work on learning organisations also on the systems approach. where people continually expand their capacity to create the results they truly desire, where new and expansive patterns of thinking are nurtured, where collective aspiration is set free, and where people are continually learning to see the whole together (Senge, 1990).

Some basic concepts of systems are shown in Figure 1. The structure of a system is described by its elements and their relations between each other. An element or a subset of elements of a system can form another system - a sub-system. Furthermore, the considered system is embedded into a larger system - the super-system to which it is a sub-system. 


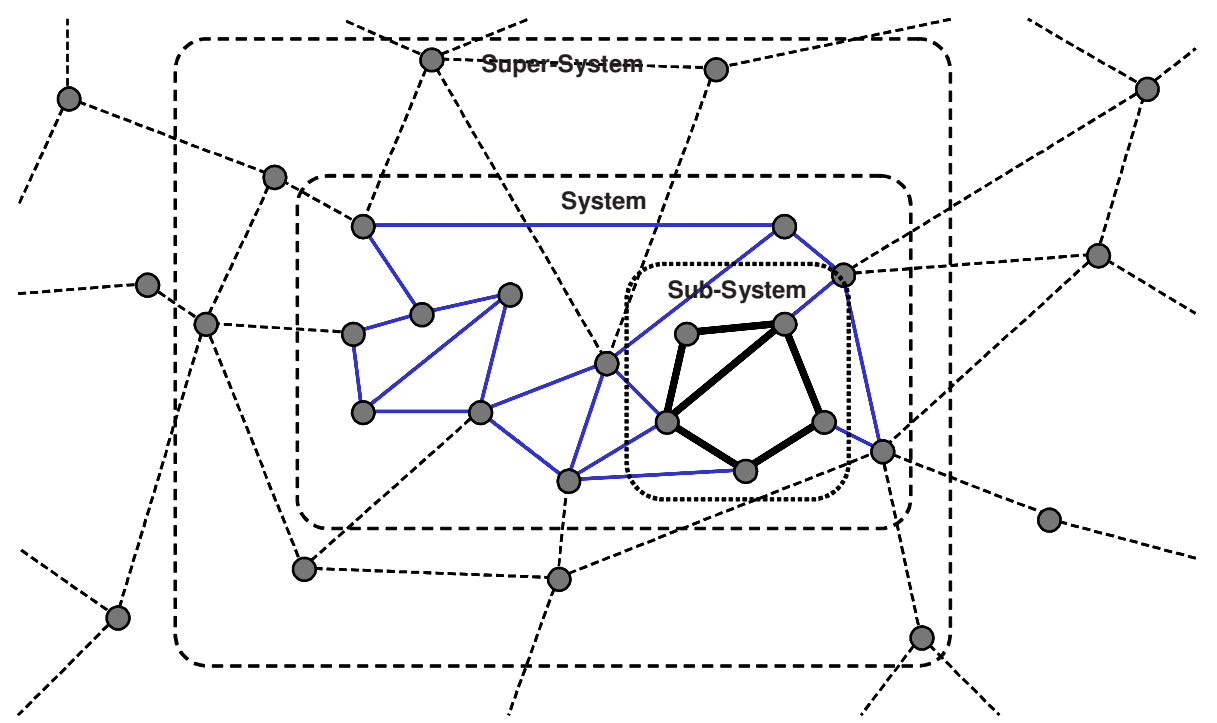

Figure 1: Structural Concepts of Systems

Ropohl proposes three different aspects (or concepts) to better understand systems (Ropohl, 1999):

- Structural system concept: Within this concept, the analysis of systems focuses on the single elements and the relations between them.

- Functional system concept: The functional concept focuses on the behaviour emerging from the system structure. As behaviour only occurs over time, this concept also considers the dynamics of the system.

- Hierarchical system concept: This concept analyses the hierarchical structure of the system, i.e. what is included, what are the sub-systems and what is the system environment (super-system).

Further, there are four basic principles of general systems theory:

- A system is more than the simple sum of its parts (elements and relations). The system is a holistic unit. The number of relations describes the character of the system.

- The structure of the system which is defined by the elements and their relations determines the function (behaviour) of the system.

- The function of the system can be created by different structures. Different structures might show the same behaviour (structural equivalence).

- It is impossible to fully describe a system with only one of three concepts (impossible reductionism).

Systems show some characteristics like openness, complexity, ordered structure, steerability, self organisation, and meaningfulness (Wegehaupt, 2004; p. 31). 


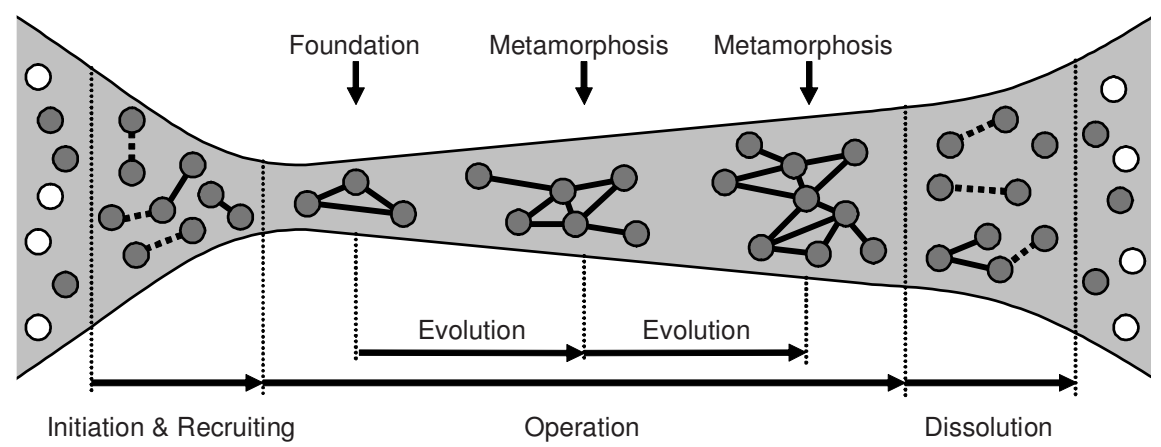

Figure 2: VBE Life Cycle

\subsection{VO Breeding Environments (VBEs)}

VBEs have been described in recent literature (e.g. Klen et al., 2006; Afsarmanesh and Camarinha-Matos, 2005). Within the VBE several actors and their roles have been identified so far: Members, VBE Administrator, Broker, VO Planner, and VO Coordinator. Duin suggests to also establish a Steering Committee headed by the VBE Administrator (Duin, 2007).

The life cycle of a VBE as shown in Figure 2 consists of three main phases: Initiation and Recruiting, Operation and Dissolution. The dissolution of the VBE is a rare event, instead a VBE changes by metamorphosis (Afsarmanesh and CamarinhaMatos, 2005).

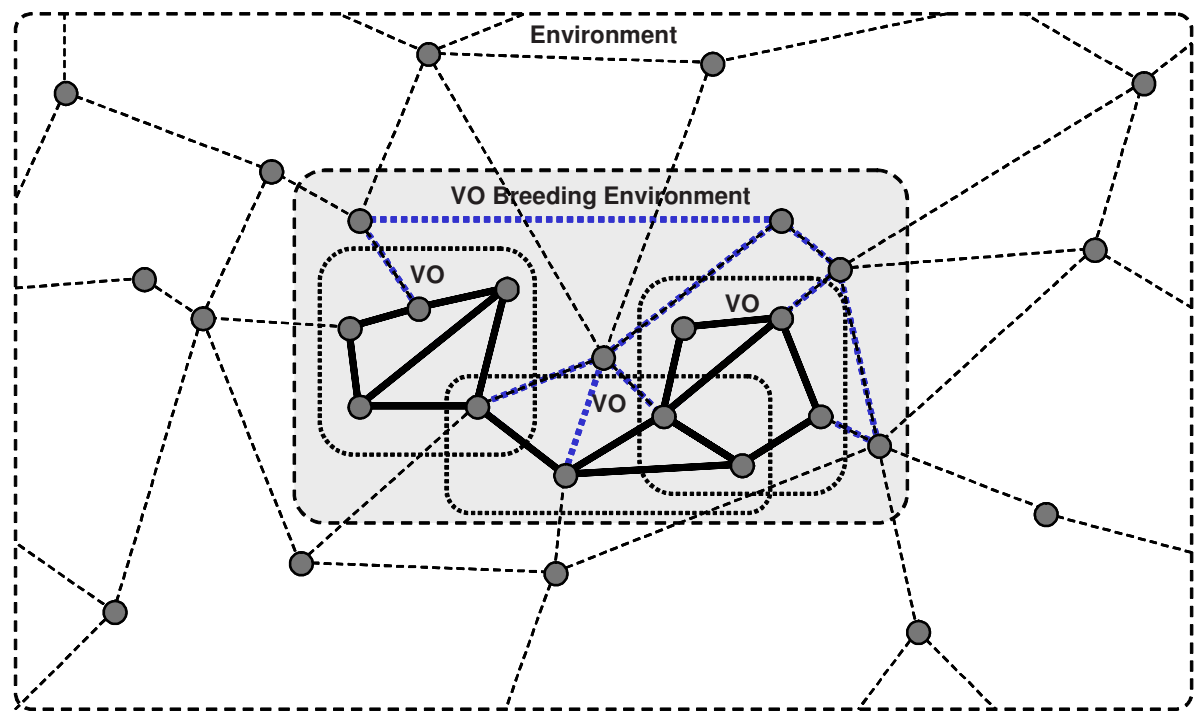

Figure 3: A Systemic View on the VBE

For a better understanding of the systemic approach applied to view the VBE concept, the following observations can be made: 
- The existence of a VBE is generally long-term and therefore needs some kind of strategic management. The points in time, when strategic decisions have to be made are the foundation and each of the metamorphosis steps.

- The VBE is a non- focal CNO. This means, it follows a heterarchic concept. Ideally all members are involved in strategy development.

- Dynamics occurs in evolution once the system as a stable phase. Instability can be solved by metamorphosis, which is a radical change of the structure of the system with the goal to become stable again.

- $\quad$ Each single VBE is focussed on a specific domain, sector or market. In this paper, the focus is set to manufacturing, i.e. the production of goods and/or services.

- VBEs can be of different size ranging from a few members to several thousands. This paper addresses small/medium sized VBEs (3 to 100 members).

An application of the concepts and principles mentioned in chapter 2.1 to VBEs reveals some basic observations, which are given in Table 1.

\begin{tabular}{|c|c|}
\hline Concepts & Observations \\
\hline Structural Concept & $\begin{array}{l}\text { The structure of the system consists of the members and their rela- } \\
\text { tions. The relations include issues resolved in a cooperation agree- } \\
\text { ment, a common infrastructure and the sharing principles. }\end{array}$ \\
\hline \multirow[t]{2}{*}{ Functional Concept } & $\begin{array}{l}\text { The main function of the VBE is to enhance the preparedness of its } \\
\text { members to form a VO on the appearance of business opportunities. }\end{array}$ \\
\hline & $\begin{array}{l}\text { This implies, that the success of the VBE might be measured in the } \\
\text { turnover generated by VOs created from the VBE. }\end{array}$ \\
\hline \multirow[t]{3}{*}{ Hierarchical Concept } & The system under consideration is the VBE itself. \\
\hline & $\begin{array}{l}\text { The elements are the members of the VBE. The relations are the ex- } \\
\text { change of information, physical goods and trust. Each member can be } \\
\text { seen as a sub-system (as it is normally an organisation, which is a } \\
\text { system in itself). But, also the VOs created in the context of the VBE } \\
\text { are sub-systems. }\end{array}$ \\
\hline & $\begin{array}{l}\text { The super-system, where the VBE is embedded in, consists of the } \\
\text { specific market, the different national societies, and last but not least } \\
\text { the eco-system world. }\end{array}$ \\
\hline Principle & Observations \\
\hline Holistic Unit & $\begin{array}{l}\text { The VBE itself is something new and can be viewd as a unit. Viewed } \\
\text { from the outside, a VBE seems to be an (networked) organisation. }\end{array}$ \\
\hline System Function & $\begin{array}{l}\text { As the objective of a VBE is to respond to occurring business oppor- } \\
\text { tunities by creating appropriate VOs, the structure of its membership } \\
\text { must be adequate, i.e. the competencies not only for working in an } \\
\text { networked organisation but also for the selected domain must be } \\
\text { present. }\end{array}$ \\
\hline Structural Equivalency & $\begin{array}{l}\text { The exchange (inclusion and/or exclusion) of members changes the } \\
\text { structure but may not affect the function. Different settings may show } \\
\text { different efficiency and/or effectiveness. If the system function (e.g. } \\
\text { by defining new strategic objectives like the addressed sector) needs } \\
\text { to be changed, this has to be done changing the structure. }\end{array}$ \\
\hline Impossible Reductionism & N/A \\
\hline
\end{tabular}

Table 1: Application of System Concepts and Principles to a VBE 


\section{REQUIREMENTS WITHIN STRATEGIC MANAGEMENT}

\subsection{The Strategic Management Process}

The strategic management process consists of strategy planning, implementation and controlling. Strategy planning is driven by normative management, i.e. the management of vision, mission and long-term objectives (e.g. Duin, 2007).

This process needs to be applied to the networked organisation type VBE which implies, that methods and tools to support the process need to provide the ability to model adequately the system "VBE", the sub-systems "VOs" and Members and the super-system Environment in order to analyse the behaviour in a holistic way.

\subsection{Requirements Analysis}

The identification of requirements for a strategic management system for a VBE needs to support the whole process and its supporting methods and tools. Table 2 provides an overview on the requirements by applying the systemic view.

\begin{tabular}{|c|c|}
\hline Area & Requirements \\
\hline \multirow[t]{6}{*}{ General Requirements } & $\begin{array}{l}\text { The approach needs to support systemic characteristics like complex- } \\
\text { ity, modelling of inter-relationships, and the simulation of behaviour } \\
\text { (or dynamics). }\end{array}$ \\
\hline & $\begin{array}{l}\text { Hierarchic decomposition, i.e. the composition of a system by sub- } \\
\text { systems etc. This includes the differentiation between internal and } \\
\text { external view. }\end{array}$ \\
\hline & $\begin{array}{l}\text { The modelling approach should support the reduction of complexity } \\
\text { revealing the main structure and driving forces within the system. } \\
\text { Often detailed structures which have only marginal effects are not } \\
\text { important for strategic decisions. }\end{array}$ \\
\hline & $\begin{array}{l}\text { A simulation component should be available to generate scenarios } \\
\text { reflecting the effects of the implementation of strategic decisions. }\end{array}$ \\
\hline & Scenarios should be comparable. \\
\hline & $\begin{array}{l}\text { A component which explains simulation results should be available. } \\
\text { Humans often have difficulties to explain the behaviour of a system } \\
\text { by just knowing the structure. }\end{array}$ \\
\hline \multirow[t]{2}{*}{ Internal View } & $\begin{array}{l}\text { Indicators or measures reflecting the goals and the structure of the } \\
\text { VBE should be identified and modelled including their inter- } \\
\text { relationships. }\end{array}$ \\
\hline & $\begin{array}{l}\text { Action plans which represent the implementation of strategic deci- } \\
\text { sions need to be modelled. }\end{array}$ \\
\hline \multirow[t]{2}{*}{ External View } & $\begin{array}{l}\text { External factors which might influence the functions of the systems } \\
\text { need to be taken into account. These could be events which have a } \\
\text { strong influence on the success of the VBE. Typically such influences } \\
\text { come from legislation, society or technological developments. }\end{array}$ \\
\hline & $\begin{array}{l}\text { Market factors including suppliers, competitors and customers need to } \\
\text { be addressable. This may include the modelling of competing actors } \\
\text { including their action plans. }\end{array}$ \\
\hline
\end{tabular}

Table 2: Requirements for Supporting Strategic Management in VBEs 


\section{SYSTEMIC APPROACHES FOR STRATEGIC MANAGEMENT}

Strategic management is the art and science of formulating, implementing and evaluating cross-functional decisions that will enable an organisation (and we can view a VBE as an organisation) to achieve its objectives (e.g. Mintzberg, 1994).

Strategic management and strategic planning can be supported by a variety of approaches developed during the last decades. Most of them focus on specific tasks like the analysis of internal and external factors, product-market-mix (portfolio analysis), product life cycle analysis etc. (e.g. Hungenberg, 2006).

\subsection{Systems Thinking}

Many philosophers, scientists and management gurus advocate the development of systems thinking - the ability to see the world as a complex system in which it is understood that "you just can't do one thing" and "everything is connected to everything else" (e.g. Sterman, 2000). Therefore, systems thinking is the principle to view our world (or parts of this wolrd like human beings, organisations, nations, etc.) as a system with a structure, function and behaviour.

\subsection{Scenario Techniques}

Scenario techniques are based on two principles (e.g. Gausemeier et al., 1998):

- Systems thinking: Organisations must perceive their environment as a complex network of inter-related (external as well as internal) factors.

- Multiple futures: Organisations should not reduce their strategic thinking to one exact prognosticated future. Instead, alternative future scenarios should be created and considered during strategic planning.

A scenario can be seen as a generally intelligible description of a possible situation in the future, based on a complex network of influence factors. Most scenario techniques use some kind of formalisms to model the system and to generate more or less probable scenarios. They are then used to generate and evaluate strategic plans against these scenarios.

\subsection{Simulation Approaches}

Simulation is always done with an underlying model to be simulated. There are various kinds of simulation approaches, e.g. Monte-Carlo-based, discrete, or continuous simulation, Petri nets, and agent based simulations.

The underlying model provides the structure of the system while the simulation results describe the system dynamics - the system behaviour. 


\section{CONCLUSIONS}

This paper introduced the concepts and principles of systems based on the general systems theory. It then explained the emerging concept of the VBE as a source network for VOs. The systemic view is applied to the VBE concept and requirements concerning the strategic management of such kind of networks have been addressed.

\section{ACKNOWLEDGEMENS}

The author thanks the partners and the European Commission for support in the context of the ECOLEAD project, funded under contract number FP6-506958.

\section{REFERENCES}

Afsarmanesh, H. and Camarinha-Matos, L.: A Framework for Management of Virtual Organization Breeding Environments. In: Collaborative Networks and Their Breeding Environments - IFIP TC 5 WG 5.5 Sixth IFIP Working Conference on Virtual Enterprises, 26-28 September 2005, Valencia, Spain. 2005. pp 35-48.

Bertalanffy, L. v.: General System Theory: Foundations, Development, Applications. George Braziller. New York 1968.

Camarinha-Matos, L. and Afsarmanesh, H.: Collaborative Networks: Value Creation in a Knowledge Society. In: Knowledge Enterprise: Intelligent Strategies in Product Design, Manufacturing, and Management.Proceedings of PROLAMAT 2006, IFIP TC5 International Conference, June 15-17, 2006, Shanghai, China. Boston 2006. pp 26-40.

Duin, H.: Causal Cross-Impact Analysis as Strategic Planning Aid for Virtual Organisation Breeding Environments. In: Establishing the Foundation of Collaborative Networks - IFIP TC 5 Working Group 5.5 Eighth IFIP Working Conference on Virtual Enterprises, 10-12 September 2007, Guimaraes, Portugal. 2007. pp 147-154.

Forrester, J.: Principles of Systems. MIT Press. Cambridge (Massachusetts) 1968.

Gausemeier, Jürgen, Fink, Alexander and Schlake, Oliver: Scenario Management: An Approach to Develop Future Potentials. In: Technological Forecasting and Social Change. 59 (1998) 2, pp 111130 .

Hungenberg, H.: Strategisches Management im Unternehmen. Ziele - Prozesse - Verfahren. Gabler. 2006.

Jagdev, Harinder S. and Thoben, Klaus-Dieter: Anatomy of Enterprise Collaborations. In: Production Planning and Control. 12 (2001) 5, pp 437-451.

Klen, E. R., Pereira-Klen, A. and Gesser, C. E.: Towards the Sustainability of Virtual Organization Management. In: Proceedings of GCSM2006 - IV Global Conference of Sustainable Product Development and Life Cycle Engineering, Sao Carlos, Spain. 2006.

Kürümlüoglu, M., Nostdal, R. and Karvonen, I.: Base Concepts. In: Camarinha-Matos, L.; Afsarmanesh, H.; Ollus, M. (Eds.): Virtual Organizations. Systems and Practices. Springer. New York 2005, pp 11-28.

Mintzberg, H.: The Rise and Fall of Strategic Planning. 1994.

Ropohl, Günter: Philosophy of Socio-Technical Systems. In: Society for Philosophy and Technology. 4 (1999) 3, pp 59-71.

Senge, P.: The Fifth Discipline: The Art and Practice of the Learning Organization. Currency Doubleday. 1990.

Sterman, J.: Business Dynamics - Systems Thinking and Modeling for a Complex World. McGraw-Hill. 2000 .

Ulrich, H.: Management. Verlag Paul Haupt. Bern 1984.

Ulrich, H. and Krieg, W.: Das St. Galler Management Modell. Verlag Paul Haupt. Bern 1972.

Wegehaupt, P., 2004, Führung von Produktionsnetzwerken, WWW-Seite, <http://www.werkzeugbauaachen.de/de/563d2e5c6b82304ac12570340024caa9/Patrick_2004.pdf $>$, Accessed February 12, 2007. 